\title{
Three-dimensional Simulation of Flow and Combustion for Pulverised Coal Injection
}

\author{
Baoyu GUO, Paul ZULLI, ${ }^{1)}$ Harold ROGERS, ${ }^{2)}$ John G. MATHIESON ${ }^{1)}$ and Aibing YU \\ Centre for Computer Simulation and Modelling of Particulate Systems, School of Materials Science and Engineering, \\ University of New South Wales, Sydney, NSW 2052, Australia. \\ 1) BlueScope Steel Research, Port Kembla NSW 2505,
} Australia.

2) BHP Billiton - Newcastle Technology Centre, Shortland 2307, Australia.

(Received on April 20, 2005; accepted on June 16, 2005)

\begin{abstract}
A three-dimensional numerical model of pulverised coal injection has been developed for simulating coal flow and combustion in the tuyere and raceway of a blast furnace. The model has been used to simulate previously reported combustion tests, which feature an inclined co-axial lance with an annular cooling gas. The predicted coal burnout agrees well with that measured for three coals with volatile contents and particle size ranging between 20.2-36.4\% and particle sizes 1-200 $\mu \mathrm{m}$. Many important phenomena including flow asymmetry, recirculating flow and particle dispersion in the combustion chamber have been predicted. The current model can reproduce the experimental observations including the effects on burnout of coal flowrate and the introduction of methane for lance cooling.
\end{abstract}

KEY WORDS: pulverised coal injection; numerical modelling; coal combustion; blast furnace.

\section{Introduction}

Pulverised coal (PC) has been widely used as a tuyere injectant in ironmaking blast furnaces since the early 1980 s. The initial injection rates were typically low, thus sufficient mixing of PC and hot blast streams occurs to provide adequate oxidant for the gaseous volatile and char combustion processes. Recent efforts have focussed on increasing injection rates to $200 \mathrm{~kg} / \mathrm{t}-\mathrm{HM}$, including maximising the burnout of PC in the raceway. The extent of burnout within the raceway determines the temperature in the raceway and affects the permeability near the raceway boundary. Insufficient burnout of PC may result in the unburnt char in the furnace top gas dust. ${ }^{1,2)}$ Technology to maximise coal combustion and control permeability is the key to maintaining stable operation. ${ }^{3,4)}$

Mathematical models, based on reaction kinetics of combustion as well as heat, mass and momentum balances, are regarded as one of the most useful tools for the design and optimisation of pulverised coal combustion devices. ${ }^{5)}$ Previous modelling has been mainly conducted under oneor two-dimensional conditions. In one-dimensional models, the common modelling assumption is that the raceway zone is a loosely packed, high porosity bed through which the hot blast flows as a cylindrical, non-spreading jet. ${ }^{6-8)}$ Onedimensional models do not consider the turbulent features within the raceway and surrounding packed beds, nor the divergence of the jet exiting the tuyere. Two-dimensional models consist of a coal combustion model in the blowpipe and a competing combustion model in a coke packed bed. ${ }^{9,10)}$ Two-equation turbulence models, such as the $k-\varepsilon$ or $k-l_{\mathrm{m}}$ models, are used to calculate flow features of the gas phase. The Lagrangian technique is used to calculate the turbulent dispersion, heat transfer and reactions of the coal particles. The use of a pure two-fluid model has been reported, ${ }^{11)}$ instead of the traditional Eulerian gas-
Lagrangian particle models. However, the latter method is simpler in simulating the particle dispersion, and more practical for general engineering applications, particularly for multi-dispersed particle systems. ${ }^{12}$ )

In previous experimental studies carried out by BHP Billiton-BlueScope Steel (formerly BHP), three generations of pilot-scale research have investigated pulverised coal injection (PCI) under simulated blast furnace tuyere/blowpipe/raceway conditions. ${ }^{13)}$ By using a range of coal types, a significant decline in combustion performance with decreasing coal volatile matter was found. The combustion efficiency was found to decrease with coarser grind sizing, and this trend became more pronounced for lower volatile content coal.

Numerical modelling of coal combustion paralleled the experimental programs. In the first stage, the measured streamwise evolution of temperature downstream along the duct formed the basis for validation of a three-stage blowpipe-tuyere combustion model. ${ }^{14,15)}$ However this numerical model, based on one-dimensional plug flow, over-predicted the commencement of devolatilisation and combustion of evolved volatiles. This was attributed primarily to the model assumption of the injected coal mixing uniformly with the blast. In the second stage development, an axisymmetric two-dimensional model ${ }^{16)}$ was able to predict correctly the trend of decreasing burnout with increasing coal injection rate, although the values predicted were approximately $10 \%$ higher than those found experimentally. These investigations suggested that the mixing of the coal with the blast was critical in achieving the highest degree of coal burnout. The combustion model was extended to describe particle flow and combustion across a raceway. ${ }^{17)}$ This upgraded model did not include coke combustion within the raceway, but rather assumed a typical raceway gas composition. The model results suggested that the majority of the coal particles injected upstream of the tuyere move across 
the raceway with some degree of divergence. As a result, oxygen contained in the blast is better able to diffuse into the plume and contact coal than in the case of plug flow.

To replicate the expanding coal plume within the raceway indicated by Haywood et al., ${ }^{17)}$ experimental work commenced on a third generation test rig. The major change was the introduction of larger diameter combustion chamber to allow natural expansion of the blast and coal plume after exiting a ceramic tuyere. Provisions for the study of double and coaxial lances (cooling gases in the anulus) were also made. With this rig, the gross trends in combustion performance with respect to volatile matter were markedly different from those obtained previously. Significantly higher burnouts across a wide range of coal volatile contents were recorded, most probably associated with the expanding entry into the combustion chamber.

The attainment of high levels of coal combustion in the confined space of the tuyere and raceway requires intimate mixing of the coal particles and oxygen. For this reason, various options including lance arrangements (single/double lance, lance tip structure), local oxygen enrichment (by using oxy-coal lance, ${ }^{18)}$ supplementary fuel injection ${ }^{19)}$ and other modifications of lance design ${ }^{10}$ have been subjects of recent research activities. However, a fundamental understanding of the effect of these options on the combustion behaviour and further optimisation of injection practice necessitated a more practical three-dimensional Computational Fluid Dynamics (CFD) model. Limited information is available from studies on three-dimensional analysis of gas flow in the raceway region, ${ }^{20)}$ and combustion in blowpipe. ${ }^{18)}$

The present study aims to develop such a three-dimensional model for detailed computation of flow and combustion of PC within the tuyere and region near the tuyere nose within the raceway. The model is also able to incorporate such features as oxygen enrichment and a second gaseous fuel. This study focuses primarily on the validation of the model against the available experimental data obtained from the third generation BHP Billiton-BlueScope Steel test rig. In addition, the flow structures and evolution of the coal particles are analysed in detail.

\section{Model Description}

The major constituting components of a PCI model as a unit process include fluid mechanics, reaction of coal particle, gaseous reaction and heat transfer, which are outlined below.

\subsection{Governing Equations for Gas Phase}

The gas phase flow field is described by transport equations of the continuous phase, i.e., three-dimensional, steady-state Reynolds-averaged Navier-Stokes equations, closed by the RNG $k-\varepsilon$ turbulence model equations, based on the framework of software package ANSYS-CFX ${ }^{\mathrm{TM}}$ version 4.4. ${ }^{21)}$ Governing equations solved for the gas phase include mass, momentum, turbulence kinetic energy, turbulence dissipation rate, enthalpy, and a number of species mass fractions.

Coal combustion is determined by combining a particle transport calculation of the coal particle with an eddy break-up calculation of the combustion of the volatile gases in the gas phase. Two separate gases are given off by the particle, the volatiles and char oxidation products. The volatiles evolved during coal devolatilisation were assumed to react by a single global reaction to form carbon dioxide and water vapour. In a general form, the fuel (e.g., volatile) and oxygen are assumed to combine in a fixed stoichiometric ratio $(\alpha)$; such that:

$$
1 \mathrm{~kg} \text { fuel }+\alpha \mathrm{kgO}_{2} \rightarrow(1+\alpha) \mathrm{kg} \text { products }
$$

The mixture fraction $f$ for the reaction can be defined by

$$
f=m_{\mathrm{F}}+\frac{m_{\mathrm{P}}}{1+\alpha}
$$

where $m$ is the mass fraction and subscripts F, O and $\mathrm{P}$ refer to fuel, oxygen and product respectively. The mean mixture fraction $F$ satisfies a conservative transport equation,

$$
\nabla \cdot(\rho \mathbf{U} F)-\nabla \cdot\left[\left(\frac{\mu_{\mathrm{T}}}{\sigma_{\mathrm{T}}}+\frac{\mu}{\sigma_{\mathrm{L}}}\right) \nabla F\right]=0
$$

where $\mu$ and $\mu_{\mathrm{T}}$ are the molecular and turbulent viscosities respectively, and $\sigma_{\mathrm{L}}$ and $\sigma_{\mathrm{T}}$ are the equivalent Prandtl numbers. In addition, an explicit equation is solved for the mean mass fraction of fuel, $m_{\mathrm{F}}$,

$$
\nabla \cdot\left(\rho \mathbf{U} m_{\mathrm{F}}\right)-\nabla \cdot\left[\left(\frac{\mu_{\mathrm{T}}}{\sigma_{\mathrm{T}}}+\frac{\mu}{\sigma_{\mathrm{L}}}\right) \nabla m_{\mathrm{F}}\right]=R_{\mathrm{F}} \ldots \ldots \ldots
$$

where $R_{\mathrm{F}}$ is the combustion rate, determined by ${ }^{22)}$

$$
R_{\mathrm{F}}=-23.6\left(\frac{\mu \varepsilon}{\rho k^{2}}\right)^{1 / 4} \frac{\varepsilon}{k} \min \left(m_{\mathrm{F}}, \frac{m_{\mathrm{O}}}{\alpha}\right) .
$$

where $k$ is turbulent kinetic energy and $\varepsilon$ is dissipation rate. For the coal combustion model with a second fuel, there are 6 transport equations for species mass fractions, i.e., volatiles, fuel-2, combustion scalar-1, combustion scalar-2, char oxidation product and $\mathrm{N}_{2}$.

\subsection{Particle Transport}

In contrast, pulverised coal particles are treated as a dispersed phase using the Lagrangian method, by which particle behaviours are calculated along the discrete particle trajectories without interaction between particles. The trajectories of the discrete particles are determined by integrating Newton's second law, where the drag force is the main force component. A number of representative particles are tracked sequentially one-by-one through a steady state gas flow field. The coal particles are treated as non-interacting spheres with uniform temperature and composition. Full coupling of mass, momentum and energy of the particles with the gaseous phase is carried out. The turbulent effect is included within the particle transport model using the random walk method of Gosman and Ioannides. ${ }^{23)}$

The combustion of a coal particle is a two-stage process: the devolatilisation of the raw coal particle is followed by the oxidation of the residual char. It is assumed that the volatiles and char evolved during devolatilisation react respectively by a single global reaction to form carbon dioxide and water vapour.

\subsection{Devolatilisation}

The model of Ubhayakar et al. ${ }^{24)}$ was chosen, wherein a pair of reactions with different rate parameters and volatile yields compete to pyrolyse the raw coal:

$$
\text { Coal } \underset{k_{2}}{\stackrel{k_{1}}{\longrightarrow}} \alpha_{1} \alpha_{2} V_{2}+\left(1-\alpha_{1}\right) C h_{1}
$$

where $k_{1}$ and $k_{2}$ are reaction rate constants at low tempera- 
Table 1. Constants in the two-competing reaction model.

\begin{tabular}{|c|c|c|c|c|}
\hline Reaction & $\alpha_{i}$ & $\mathrm{~A}\left[\mathrm{~s}^{-1}\right]$ & $\mathrm{E}[\mathrm{K}]$ & Reference \\
\hline \multirow[t]{4}{*}{1} & $\mathrm{Vm}$ & $3.7 \times 10^{5}$ & 8852 & Ubhayakar et al. $^{24)} ; \mathrm{Li}$ et al. ${ }^{11)}$ \\
\hline & 0.39 & $3.7 \times 10^{5}$ & 8852 & CFX-4 \\
\hline & $\mathrm{Vm}$ & $1.34 \times 10^{5}$ & 8852 & Jamaluddin et al. $^{15)}$ \\
\hline & Vm & $3.7 \times 10^{5}$ & 18000 & Aoki et al. ${ }^{25)}$; Current work \\
\hline \multirow[t]{3}{*}{2} & 0.8 & $1.46 \times 10^{13}$ & 30189 & CFX-4; Li et al. ${ }^{11)}$ \\
\hline & $2 * \mathrm{Vm}$ & $1.46 \times 10^{13}$ & 30189 & Ubhayakar et al. $^{24)}$ \\
\hline & $0.14+1.6 \mathrm{Vm}$ & $1.46 \times 10^{13}$ & 30189 & Current work \\
\hline
\end{tabular}

ture and high temperature respectively. The conversion rate of the raw coal is determined by:

$$
\frac{d C_{\mathrm{O}}}{d t}=-\left(k_{1}+k_{2}\right) C_{\mathrm{O}}
$$

The rate of volatiles production is given by:

$$
\frac{d V}{d t}=\left(\alpha_{1} k_{1}+\alpha_{2} k_{2}\right) C_{\mathrm{O}}
$$

and the rate of char formation is:

$$
\frac{d C h}{d t}=\left(\left(1-\alpha_{1}\right) k_{1}+\left(1-\alpha_{2}\right) k_{2}\right) C_{\mathrm{O}}
$$

where $C_{\mathrm{O}}$ is the mass of the unreacted raw coal remaining in the particle, and its initial value is equal to the ash-free mass of the particle. To reflect the coal properties, the values for $\alpha_{1}$ and $\alpha_{2}$, are not constant but are related to the content of volatiles determined from the proximate analysis of the coals. The rate constants $k_{1}$ and $k_{2}$ have Arrhenius form:

$$
k_{1} \quad \text { or } \quad k_{2}=A \exp \left(-E / T_{\mathrm{p}}\right)
$$

where $T_{\mathrm{p}}$ is the particle temperature. Parameters required for this model are listed in Table 1, namely, yield $\left(\alpha_{i}\right)$, Arrhenius rate constant $(A)$ and activation energy $(E)$. Those from the literature are also provided for comparison.

\subsection{Char Oxidation}

Char combustion is a much slower process than devolatilisation, and it therefore determines the burnout time of the pulverised coal in the furnace. The char oxidation model according to $\mathrm{Gibb}^{26}$ is used. The model equations are detailed in Ref. 21) and given below for completeness. The parameters related to the char particle structure include void fraction $(e)$, volume/internal surface area ratio $(a)$ and the effective internal diffusion coefficient $\left(D_{\mathrm{p}}\right)$ of oxygen within the pores. The oxidation mechanism of carbon can be characterised by the parameter $\phi$ so that

$$
\phi \mathrm{C}+\mathrm{O}_{2} \rightarrow 2(\phi-1) \mathrm{CO}+(2-\phi) \mathrm{CO}_{2}
$$

The value of $\phi$ is assumed as:

$$
\frac{2(\phi-1)}{2-\phi}=A_{\mathrm{S}} \exp \left[-\frac{T_{\mathrm{S}}}{T_{\mathrm{p}}}\right]
$$

where the constants are given by $\mathrm{Gibb}^{26)}$ as $A_{\mathrm{S}}=2500$ and $T_{\mathrm{S}}=6240 \mathrm{~K}$.

An analytical solution of the oxygen diffusion equation leads to the following equation for the rate of change in char mass $\left(m_{\mathrm{c}}\right)$ :

$$
\frac{d m_{\mathrm{c}}}{d t}=-\frac{3 \phi}{1-e} \frac{M_{\mathrm{C}}}{M_{\mathrm{O}_{2}}} \frac{\rho_{\infty}}{\rho_{\mathrm{c}}} \frac{m_{\mathrm{c}}}{\frac{1}{k_{1}}+\frac{1}{k_{2}+k_{3}}}
$$

The far field oxygen concentration $\rho_{\infty}$ is taken to be the mean value in the local control volume obtained from the gas phase calculation, and $\rho_{\mathrm{c}}$ is the char density. Physically, $k_{1}$ is the rate of external diffusion, $k_{2}$ is the surface reaction rate and $k_{3}$ represents the rate of internal diffusion and surface reaction. These are defined as follows:

$$
k_{1}=\frac{D}{R_{\mathrm{p}}^{2}}
$$

where $D$ is the external diffusion coefficient of oxygen in the surrounding gas;

$$
k_{2}=(1-e) \frac{k_{\mathrm{c}}}{R_{\mathrm{p}}}
$$

where $k_{\mathrm{c}}$ is the carbon oxidation rate, defined by

$$
k_{\mathrm{c}}=A_{\mathrm{c}} T_{\mathrm{p}} \exp \left[-\frac{T_{\mathrm{c}}}{T_{\mathrm{p}}}\right] \text {. }
$$

The model constants are taken to be $A_{\mathrm{c}}=14 \mathrm{~m} / \mathrm{s}$ and $T_{\mathrm{c}}=21580 \mathrm{~K}$. Further,

$$
k_{3}=k_{\mathrm{c}} T_{\mathrm{p}}(\beta \operatorname{coth} \beta-1) / \beta^{2} a
$$

where

$$
\beta=R\left(\frac{k_{\mathrm{c}}}{D_{\mathrm{p}} e a}\right)^{0.5}
$$

$\mathrm{Gibb}^{26)}$ recommends a value for $D_{\mathrm{p}}$ an order of magnitude less than $D$.

\subsection{Interphase Heat Transfer}

Thermal radiation through the gas phase is calculated using the discrete transfer method. Particles may absorb or emit radiative energy depending on their temperature. Combustion of volatiles releases heat into the gas phase while the oxidation of char releases heat to the particle. Convective heat transfer due to temperature difference between fluid and particles is calculated using a semi-empirical correlation for the Nusselt number according to the well-known Ranz-Marshall equation.

\section{Simulation Conditions}

\subsection{Coal Properties}

Three pulverised coals, Coals A-C, have been used in this study. Proximate and ultimate analyses are given in Tables 2 and 3, respectively. Although all three coals have been ground to a nominal size specification of $80 \%$ passing $90 \mu \mathrm{m}$, their actual particle size distributions are obtained from laser diffraction measurement (Fig. 1) and cover a size range of $1-200 \mu \mathrm{m}$. The mean particle sizes, e.g., Sauter mean size, differ by a maximum of up to $40 \%$ between the three samples.

In the simulation, more than 30 particle size classes were sampled in the range of $1-200 \mu \mathrm{m}$, and a total of more than 
Table 2. Proximate analysis of coals.

\begin{tabular}{|l|l|l|l|}
\hline & Coal A & Coal B & Coal C \\
\hline Moisture, mass \% (ad) & 1.2 & 3.2 & 3.6 \\
\hline Volatile matter, mass \% (ad) & 19.95 & 32.5 & 35.1 \\
\hline Ash, mass \% (ad) & 9.7 & 9.8 & 6.2 \\
\hline Fixed carbon, mass \% (ad) & 69.1 & 54.5 & 55.1 \\
\hline Sulphur total, mass \% (ad) & 0.34 & 0.58 & 0.41 \\
\hline Coal phosphorus, mass \% (ad) & 0.0 & 0.0 & 0.0049 \\
\hline Gross specific energy, (ad) MJ/kg & 31.94 & 30.08 & 30.46 \\
\hline
\end{tabular}

Table 3. Ultimate analysis of coals

\begin{tabular}{|c|c|c|c|}
\hline & Coal A & Coal B & Coal C \\
\hline $\mathrm{C}$ & 89.1 & 83.5 & 82.6 \\
\hline $\mathrm{H}$ & 4.7 & 5.3 & 5.44 \\
\hline $\mathrm{N}$ & 1.7 & 1.95 & 2.15 \\
\hline $\mathrm{S}$ & 0.37 & 0.6 & 0.3 \\
\hline O (by diff) & 4.1 & 8.6 & 9.5 \\
\hline
\end{tabular}

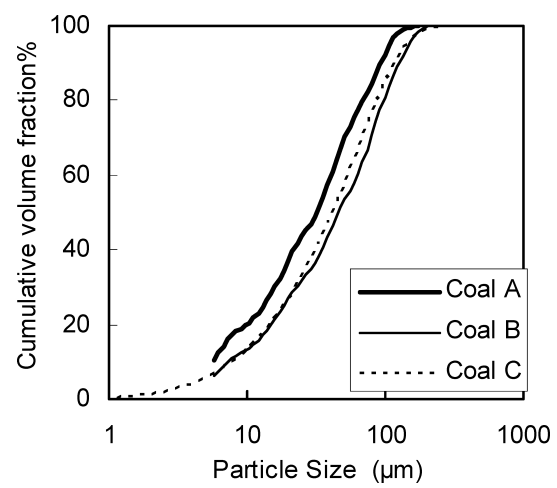

Fig. 1. Coal particle size distributions for each coal sample measured using laser diffraction sizer.

\section{0 representative particles were tracked.}

\subsection{Geometry and Boundary Conditions}

Details of the test facility used to generate the experimental data are described elsewhere. ${ }^{19}$ In the test rig, the blast duct is tapered over a length of $800 \mathrm{~mm}$ from $110 \mathrm{~mm}$ diameter to $80 \mathrm{~mm}$ immediately adjacent to the inlet of the tuyere. The injection lance is introduced into the blast duct upstream of the tuyere at an inclination of $10^{\circ}$ to the blast duct centreline with its tip bent so that the coal exits as close as possible to the centreline. The estimated inclination angle of the lance tip is about $6^{\circ}$ to the blast duct centreline. The lance reported here is made of steel tubing $12.7 \mathrm{~mm}$ OD (1.6 mm thick) with a coaxial shroud of $19.05 \mathrm{~mm} \mathrm{OD}$ (1.6 mm thick). The tuyere is $70 \mathrm{~mm}$ ID and has a length of $100 \mathrm{~mm}$. A transition section with a diverging angle of $45^{\circ}$ connects the tuyere to a combustion chamber of $300 \mathrm{~mm}$ ID.

The simulation domain for the coal combustion model is shown in Fig. 2. It was chosen to include the main sampling port and to enable the gas flow at the exit to be almost fully developed. Although the inflow boundary is defined at $100 \mathrm{~mm}$ upstream of the lance tip, the heat transfer across the lance walls is not considered for simplicity. Due to the disparate geometric and kinematic scales considered in this problem (e.g., lance and blowpipe flow domains), the heat transfer across the lance was calculated using a simplified heat transfer model without considering reactions. These results were used as boundary conditions for the coal combustion model, e.g., the temperature of the shroud outer wall. Only a segment of the lance is included in the simulation domain for flow development. The geometry and

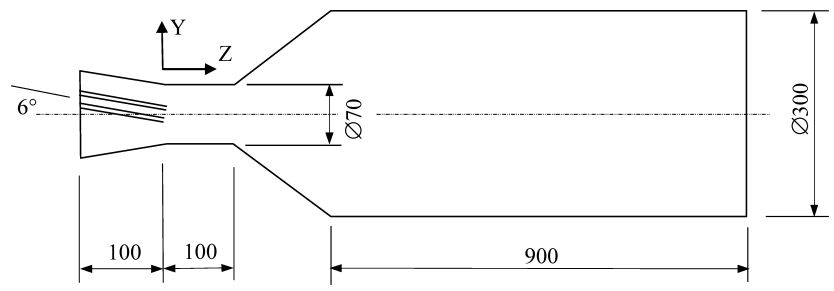

Fig. 2. Main dimensions (in $\mathrm{mm}$ ) of the coal combustion model (plan view).

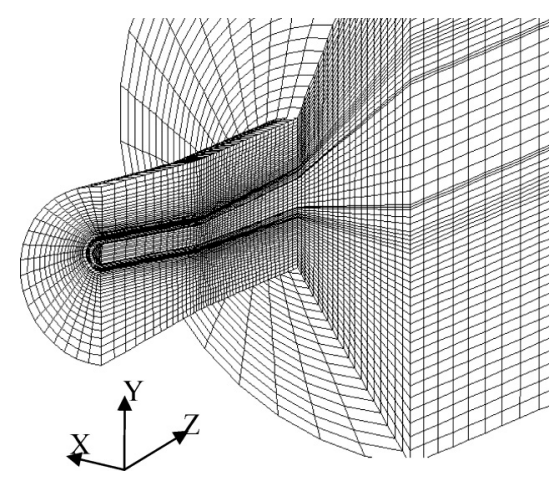

Fig. 3. A perspective view of a part of the computational mesh (vertical section)

Table 4. Basic boundary conditions for coal combustion model.

\begin{tabular}{|c|c|c|c|}
\hline & Flowrate, $\mathrm{Nm}^{3} / \mathrm{h}$ & Temperature, $\mathrm{K}$ \\
\hline \multicolumn{2}{|c|}{ Blast $\left(21 \% \mathrm{O}_{2}\right)$} & 300 & 1473 \\
\hline \multirow[t]{2}{*}{ Cooling gas } & $21 \% \mathrm{O}_{2}$ & 3.2 & \multirow[t]{2}{*}{600} \\
\hline & $100 \% \mathrm{CH}_{4}$ & 2.8 & \\
\hline \multicolumn{2}{|c|}{ Conveying gas $\left(100 \% \mathrm{~N}_{2}\right)$} & 2.0 & 323 \\
\hline \multicolumn{2}{|l|}{ Coal } & $\begin{array}{c}25-50 \mathrm{~kg} / \mathrm{h} \text {, case } \\
\text { dependent }\end{array}$ & 320 \\
\hline
\end{tabular}

boundary conditions are regarded as plane symmetric. A boundary-fitted, multi-block structured finite volume mesh is generated as shown in Fig. 3, where mesh points are refined at the lance tip region in order to resolve the high flow variation. The total number of finite volumes used in the computation is 58520 .

There are three different gas streams entering the domain, namely, conveying gas (nitrogen), cooling gas (compressed air or methane) and hot blast. The flowrates for all three streams are based on the experimental conditions used in the test rig. Since the injection lance is attached to the blowpipe and is exposed to the hot blast within the blowpipe, the temperature of the cooling gas will rise due to the heat transfer from the surrounding hot blast gas, blowpipe walls, etc. This temperature is assumed as $600 \mathrm{~K}$, as estimated by a simplified lance heat transfer calculation. ${ }^{27)}$ The inflow boundary conditions used are summarised in Table 4. Note: cooling gas flowrates were different for air and for methane in the experiments and these exact values are used in the simulation to allow for direct comparison. A no-slip flow and adiabatic condition are imposed at the blowpipe walls.

\section{Results and Discussion}

In this section, typical simulation results for the aircooled lance will be presented first for general analysis. The results presented are based on the conditions of Test No. 4 in Table 5, but qualitatively, the insight obtained applies to all other cases studied. Then, the effects of several 
Table 5. Comparison between calculated and experimental burnout.

\begin{tabular}{|c|c|c|c|c|c|c|}
\hline No. & Coal type & $\begin{array}{c}\text { Coal } \\
\text { flowrate, } \\
\mathrm{kg} / \mathrm{h}\end{array}$ & $\begin{array}{c}\mathrm{O} / \mathrm{C} \\
\text { ratio }\end{array}$ & $\mathrm{VM}, \%$ & $\begin{array}{c}\mathrm{B} \text { (predicted), } \\
\%\end{array}$ & $\begin{array}{c}\text { B (measured), } \\
\%\end{array}$ \\
\hline 1 & Coal A & 25.2 & 3.26 & 20.19 & 58.22 & 63.7 \\
\hline 2 & Coal A & 35.9 & 2.25 & 20.19 & 56.24 & 55.5 \\
\hline 3 & Coal B & 25.5 & 3.42 & 33.57 & 75.92 & 81.5 \\
\hline 4 & Coal B & 40.0 & 2.08 & 33.57 & 74.41 & 75.5 \\
\hline 5 & Coal B & 46.7 & 1.85 & 33.57 & 74.17 & 71.4 \\
\hline 6 & Coal C & 23.5 & 3.97 & 36.41 & 80.99 & 78.9 \\
\hline 7 & Coal C & 35.1 & 2.66 & 36.41 & 80.04 & 76.2 \\
\hline $8^{*}$ & Coal A & 23.1 & 3.2 & 20.19 & 57.52 & 53.2 \\
\hline $9^{*}$ & Coal A & 36.8 & 2.01 & 20.19 & 54.47 & 51.6 \\
\hline $10^{*}$ & Coal B & 35.8 & 2.1 & 33.57 & 74.44 & 77.7 \\
\hline $11^{*}$ & Coal C & 36.2 & 2.36 & 36.41 & 79.42 & 76.1 \\
\hline
\end{tabular}

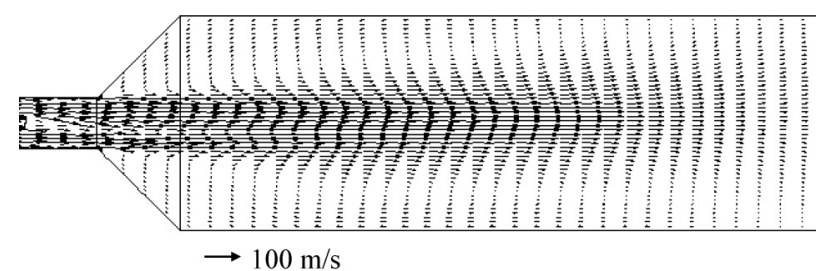

a)

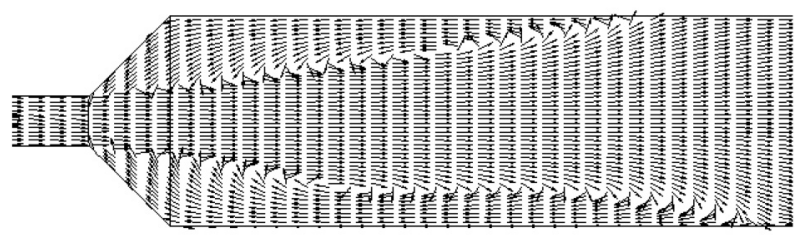

b)

Fig. 4. Gas velocity vectors in $\mathrm{Y}-\mathrm{Z}$ plane: (a) vector length to scale; (b) vector length normalised showing recirculation zone.

parameters on the overall burnout will be discussed, which involve a quantitative comparison with available experimental data.

\subsection{Gas Flow Field-Velocity Distribution}

The gas phase velocity vectors are shown in Fig. 4. The high-speed gas exiting the tuyere is shown to form a central jet. Instead of a diverging plug flow, which is uniformly distributed in the radial direction, the central jet within the divergent pipe increases only slightly in the radial direction, indicating that the current expansion angle is too large to suppress the flow separation. Moreover, the influence of the lance on the flow field is not negligible. The transport gas (for coal) has a much lower velocity than the cooling gas and blast gas, thus a low velocity wake forms in the downstream behind the lance tip. From the gas velocity field in Fig. 4, the extent of this wake expands gradually with distance rather than being mixed quickly with the main flow. Thus the gas velocity cannot achieve uniformity within the tuyere, not even after 1-2 tuyere diameters away from the tuyere nose. A large-scale recirculation zone is generated between the central jet and the wall of the combustion chamber. The recirculation zone extends a distance of about two diameters (of the large chamber) from the tuyere nose. The inclined lance creates an asymmetric global flow pattern, as can be seen from the velocity profile of the jet and the locations of the reattachment points.

\subsection{Particle Flow Pattern}

The particle flow pattern and combustion characteristics

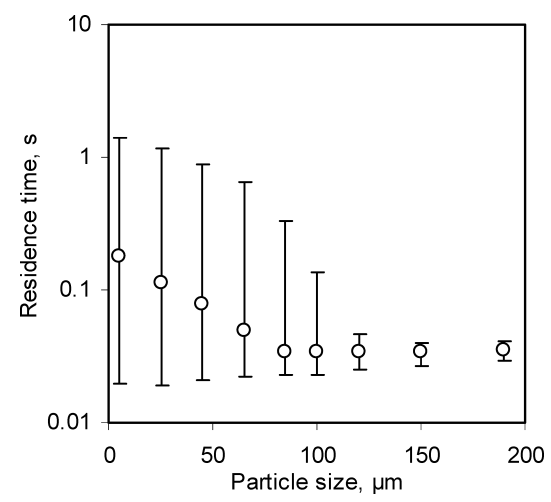

Fig. 6. Calculated particle residence time (mean and varied range) within the simulation domain.

are related to the initial coal particle sizes. Figure 5 shows typical coal particle trajectories coloured by their sizes. The particle dispersion in the tuyere region is very limited, and coal particle trajectories appear fairly regular within the tuyere, with only a slight divergence angle. The inclined lance creates an inclined plume with a cross-stream velocity component. A particle segregation phenomenon can be seen. Upon exiting the lance, large particles with higher momentum maintain their initial direction, i.e., the lance axial direction, while fine particles tend to be entrained in the blast flow and hence move in the main stream direction. The fine particles also disperse more widely, mainly because they possess lower inertia and are more easily affected by turbulence; however, their mass fraction is quite low.

In contrast, the particle flow in the large chamber displays a rather complex and chaotic pattern. The segregation phenomenon is even more obvious. Like the gas flow, particles below a certain size $(<10 \mu \mathrm{m})$ may recirculate near the chamber wall region. Some of these back-flowing particles can reach the tuyere exit plane and then be re-entrained into the central jet, while the rest may be trapped in the recirculation zone for a long time. Therefore particle residence times within the simulation domain vary greatly for different particle sizes (Fig. 6). Generally large particles have much shorter residence times than small particles, because the large particles tend to remain at the plume centre and head downstream with a high velocity, while a fraction of the fine particles are widely dispersed in space and trapped in the recirculation eddy, which results in a great dicrepancy in residence time, i.e., ranging from $25 \mathrm{~ms}$ up to $1 \mathrm{~s}$.

\subsection{Evolution of Particle Characteristics}

The burnout $(B)$, which is a measure of the extent of coal combustion, is calculated using an ash balance: 


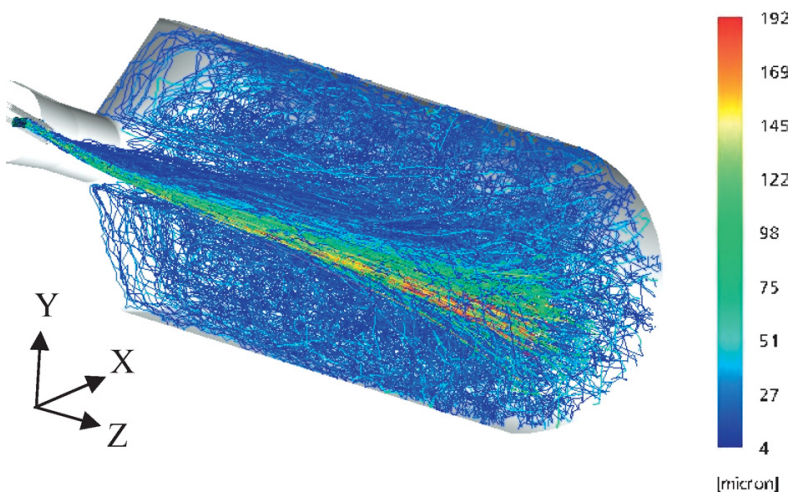

Fig. 5. Typical particle trajectories with colour scaled to particle size.

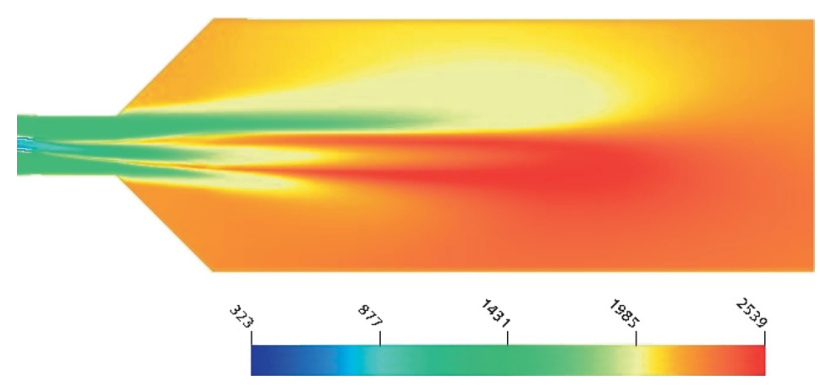

Fig. 13. Gas temperature isopleths in $\mathrm{Y}-\mathrm{Z}$ plane $[\mathrm{K}]$.

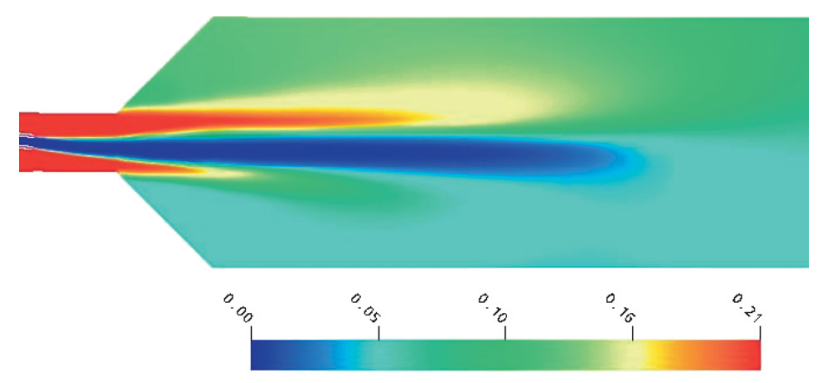

a)

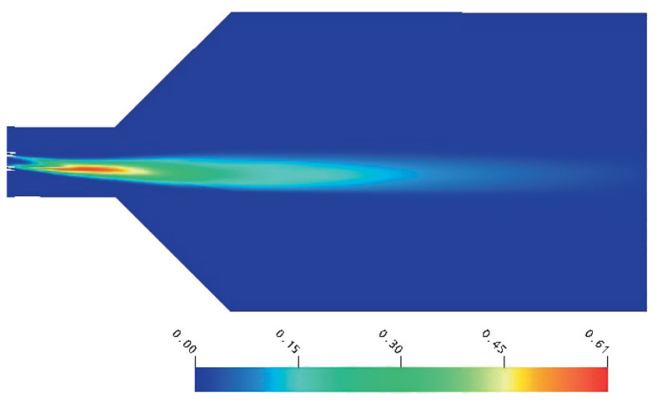

b)

Fig. 14. Gas species fraction isopleths in $\mathrm{Y}-\mathrm{Z}$ plane. (a) Oxygen; (b) volatile matter.

$$
B=\left(1-\frac{m_{\mathrm{a}, 0}}{m_{\mathrm{a}}}\right) /\left(1-m_{\mathrm{a}, 0}\right)
$$

where $m_{\mathrm{a}, 0}$ is the ash content of the original coal and $m_{\mathrm{a}}$ is the ash content of the burnt residual sampled. Both values are on a dry basis $(\mathrm{db})$ in order to compare with the test data, although the moisture is released together with the

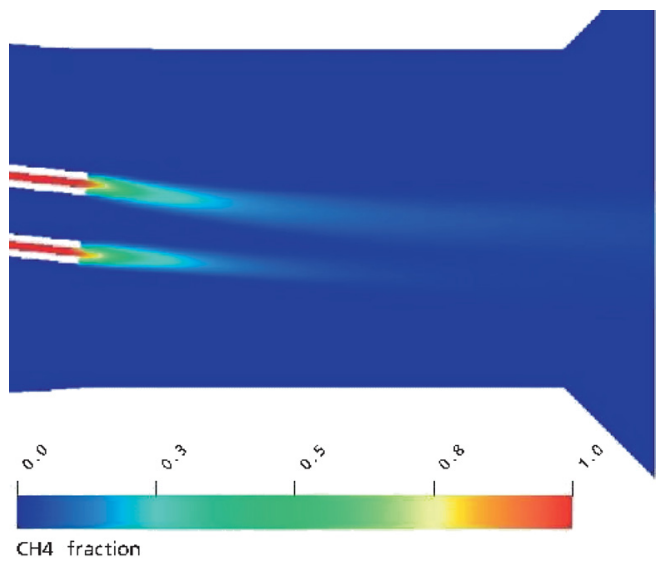

Fig. 18. Calculated mass fraction of cooling methane.

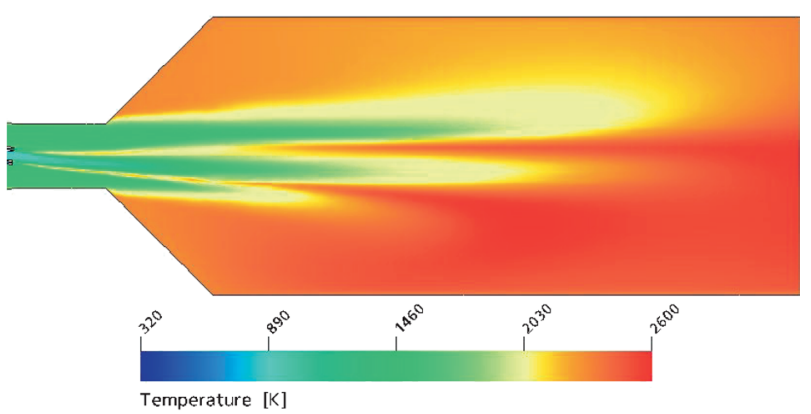

a)

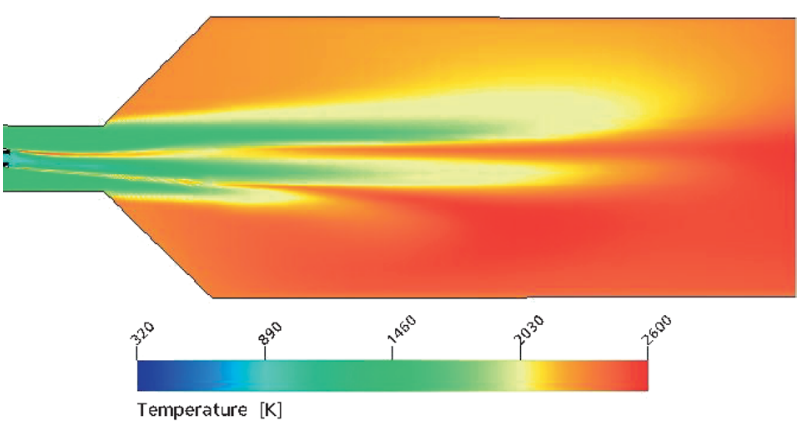

b)

Fig. 19. Comparison of temperature distribution between (a) air cooling and (b) methane cooling.

other volatiles in the model. As defined, the burnout represents the total weight loss of the organic fraction of the coal due to volatile release and char reaction.

Figures 7-9 show the time evolution of particle characteristics such as temperature, burnout and volatile matter content for Coal B. For each particle size fraction, three stages in the coal combustion process are evident, i.e., preheating, fast devolatilisation and slow char oxidation. The heating rate of particles is strongly dependent on particle size during the first two stages. Compared with coarse particles, fine particles with a higher surface area/mass ratio have a high heat transfer rate per unit mass of coal, leading to a rapid temperature rise. Coal starts to pyrolyse at approximately the same temperature of $1000-1100 \mathrm{~K}$ for all particle sizes, so for large particles, this process is delayed. The end point for pyrolysis, however, is not directly related to particle temperature; rather it is a result of the temperature history of a particle. 


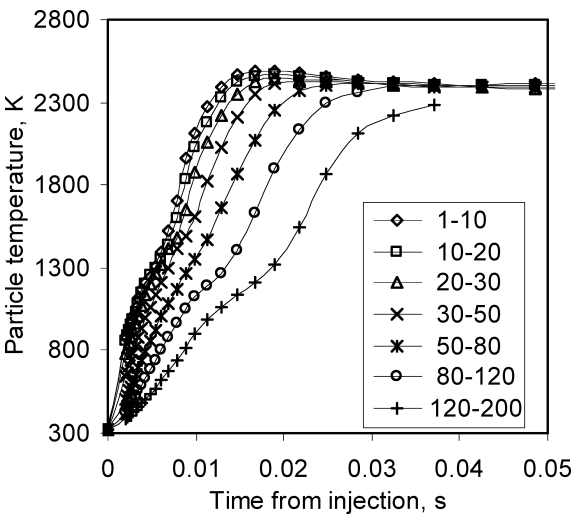

Fig. 7. Calculated mean particle temperatures as a function of transit time for different size fractions (in $\mu \mathrm{m}$ ).

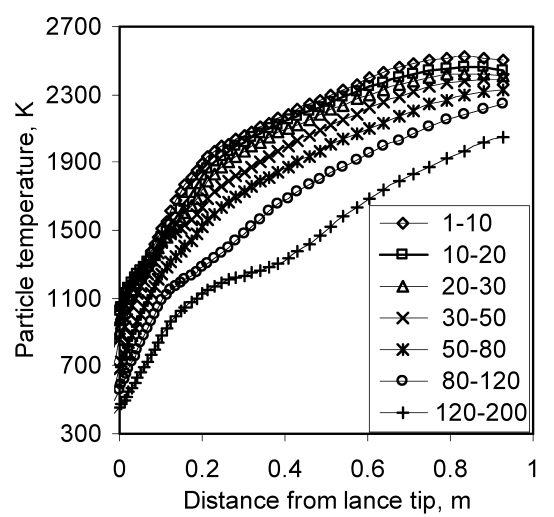

a)

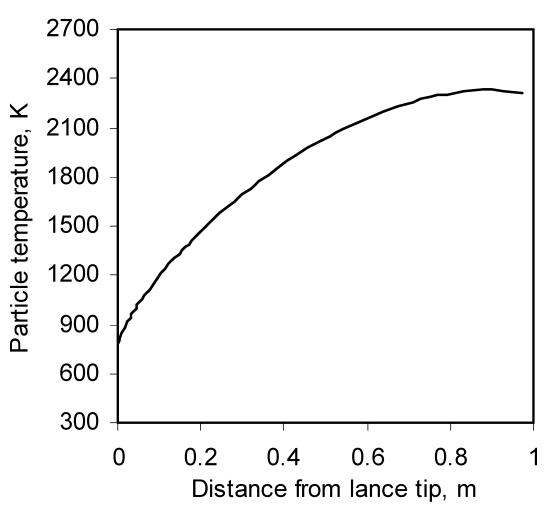

b)

Fig. 10. Calculated mean particle temperature as a function of distance from the lance tip along the centreline averaged (a) for different particle sizes (in $\mu \mathrm{m}$ ) and (b) for all particles.

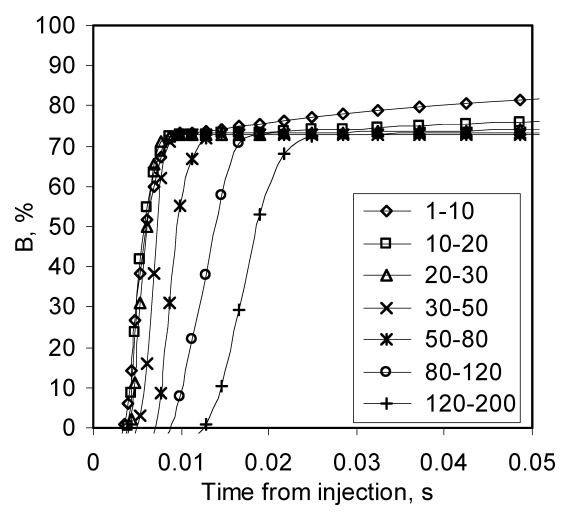

Fig. 8. Calculated mean particle burnout as a function of transit time for different size fractions (in $\mu \mathrm{m}$ ).

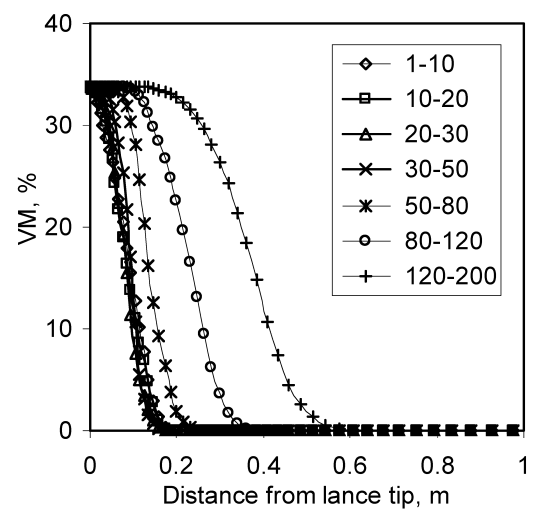

a)

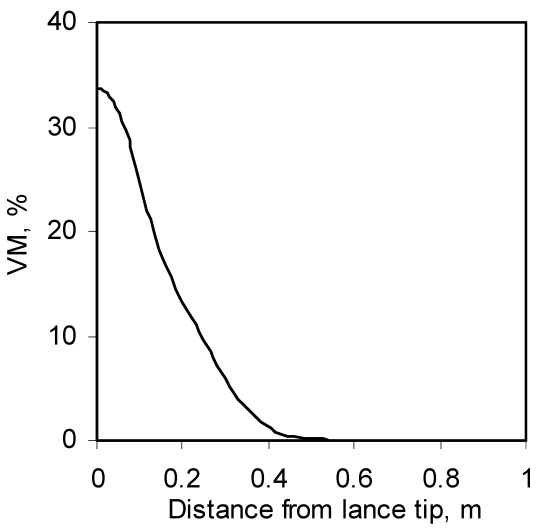

b)

Fig. 11. Calculated mass fraction of volatiles as a function of distance from the lance tip along the centreline averaged (a) for different particle sizes (in $\mu \mathrm{m}$ ) and (b) for all particles.

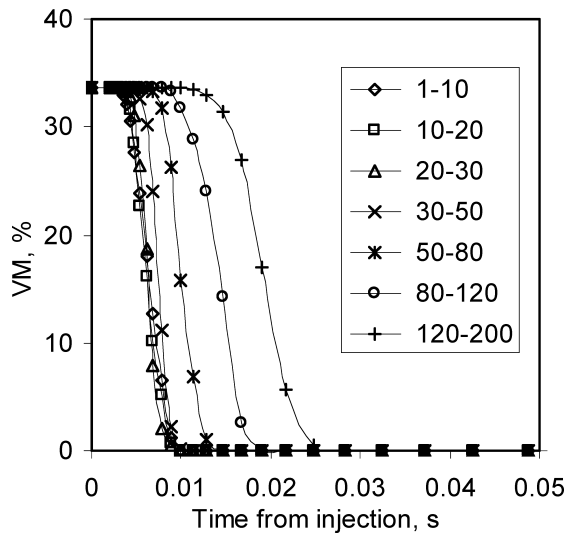

Fig. 9. Calculated mean volatile matter as a function of transit time for different size fractions (in $\mu \mathrm{m}$ ).

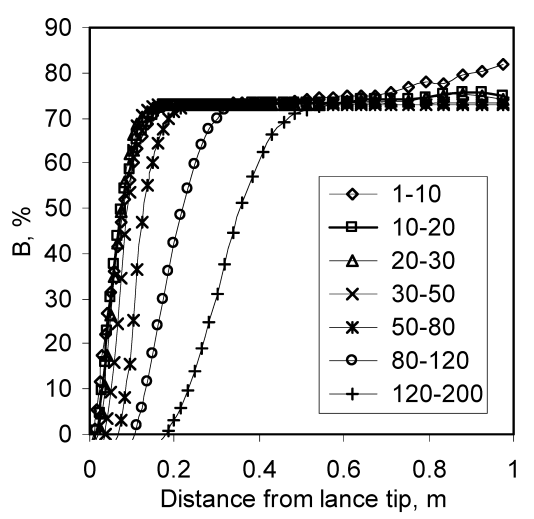

a)

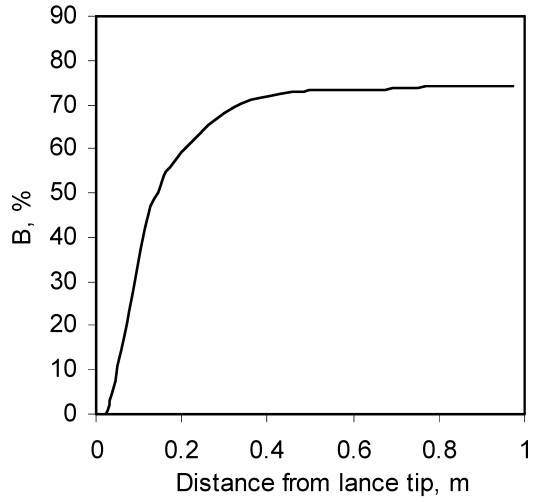

b)

Fig. 12. Calculated mean particle burnout as a function of distance from the lance tip along the centreline averaged (a) for different particle sizes (in $\mu \mathrm{m}$ ) and (b) for all particles.
Particle temperature not only affects the rate of raw coal combustion, but also the ratio of volatile to char carbon. The temperature variation between different particle size fractions causes the burnout to vary significantly during the initial $20 \mathrm{~ms}$. Interphase heat transfer is critical to the burnout rate. However, the difference in burnout becomes less pronounced when coal pyrolysis is completed. At this point, the particle temperatures are almost equal and the combustion rate is controlled by char oxidation. Nonetheless, the model indicates that fine particles burnout faster than coarse particles for two reasons. First, fine parti- cles have relatively large surface areas for contact and reaction with oxygen. Second, fine particles disperse more widely due to the turbulence effect, and subsequently move into the oxygen-richer regions. As mentioned earlier, the trajectories of large particles are less affected by turbulence and thus, these particles remain in regions of oxygen depletion, e.g., central core of the plume.

Particle properties at any point in space can be approximated by the averaged properties over all the particles that pass a circular cross-section with a small diameter $(50 \mathrm{~mm})$. Figures 10-12 show the particle characteristics as a func- 
tion of axial distance from the lance tip along the centreline. In the model, all representative particles are randomly introduced within the internal tube of the lance $50 \mathrm{~mm}$ upstream of the lance tip. The initial particle velocity is set at $15 \mathrm{~m} / \mathrm{s}$ ( similar to the conveying gas velocity) in a direction fixed by the lance inclination. Particles are preheated from $320 \mathrm{~K}$ to an average temperature of $800 \mathrm{~K}$ before exiting the lance. The temperature rise of particles within the lance is attributed mainly to back-radiation from the combustion flame. Fine particles are heated to a higher temperature than coarse particles and may pyrolyse within the lance tube. Figure 10 shows the mass-weighted mean particle temperatures as a function of axial distance from the lance tip. The particle temperature at the centreline increases consistently with distance before approaching an asymptote near the outlet. The initial heating rate and the subsequent particle temperature vary according to particle size, with fine particles being always hotter than large particles. Particles less than $20 \mu \mathrm{m}$ begin to burn almost immediately near the lance exit, while large particles, above $80 \mu \mathrm{m}$, only start to burn after leaving the tuyere. At $0.2 \mathrm{~m}$, particles below $30 \mu \mathrm{m}$ have nearly completed devolatilisation, whereas those above $80 \mu \mathrm{m}$ have hardly started (Fig. 11). Up to $0.5 \mathrm{~m}$ from the lance tip, the burnout levels are significantly different for particles of different sizes (Fig. 12); however, beyond $0.5 \mathrm{~m}$, there is little variation-at this distance, slow char oxidation is prevalent.

\subsection{Gas Phase-distribution of Temperature and Con- centration}

Figures 13 and 14 show the gas temperature distribution, and oxygen and volatile matter distributions in the gas phase, respectively. All quantities vary in the radial direction as well as in the axial direction. The inclined lance and coal plume cause the flow field to be asymmetric, such that higher temperatures and lower oxygen concentrations always occur in the lower half region. The oxygen concentration in the coal plume region is always low as the combustion of the volatile and char oxidation consume oxygen. Thus the transport of oxygen primarily controls the combustion rate. An annular region of high temperature (or the so called 'flame front') is formed at the plume surface, where higher oxygen content causes rapid burning of volatiles and release of heat. This flame front is even more pronounced when using pure oxygen as the cooling gas.

A fuel-rich core exists and is surrounded by a high temperature reaction zone. In this oxygen-depleted region, a very high heating rate caused by the surrounding hot gas leads to a rapid generation of volatile gases, so that volatile matter builds up. Volatile matter may be evolved inside the lance, especially from fine particles. On the other hand, combustion is impossible in the absence of oxygen, thus combustion products can only be observed beyond the lance tip.

\subsection{Radial Profile of Burnout}

In the experiment, samples are collected for analysis at five radial positions from one sampling port, i.e., +125 $\mathrm{mm},+50 \mathrm{~mm}, 0,-50 \mathrm{~mm}$ and $-125 \mathrm{~mm}$ relative to the centreline at $925 \mathrm{~mm}$ from the tuyere inlet plane. The burnout of coal sampled at various radial positions varies as shown in Fig. 15. The sampling point location refers to the horizontal distance with respect to the chamber centreline. These data points are obtained by averaging over a number of cases with an air-cooled lance. The profile is asymmetric due to the inclined lance and hence coal plume. A mini-

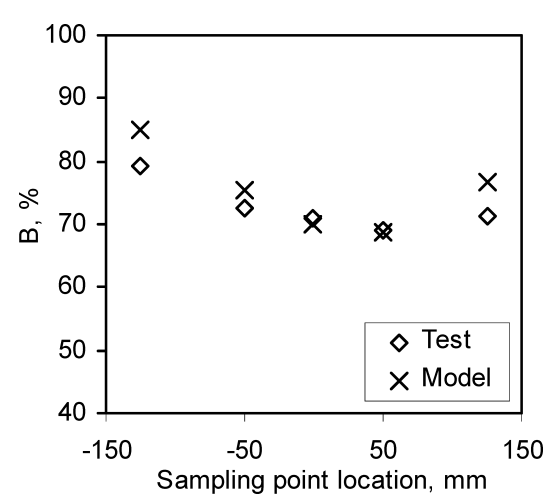

Fig. 15. Burnout at different radial locations.

mum burnout occurs at the plume centre, which is approximately $50 \mathrm{~mm}$ off the centreline and is the location where more large particles are present. The particle burnout increases towards the chamber wall, since the particles collected at the near wall region are small in size and most of them may have undergone reaction for a long period of time (i.e. long residence time). A similar trend exists between the model and experimental results, with the model results producing a more distinct radial variation.

The numerical model generates more detailed information than measured for each case, which assists in understanding the global trends with respect to various variables. The accuracy of the model is further verified using test data under different operating conditions in Sec. 4.6. A more extensive systematic parametric study will be conducted in future work.

\subsection{Effects of Several Variables}

\subsubsection{Overall Burnout}

The experimental values for overall burnouts, $\mathrm{B}$, are averages of three radial points $(+50 \mathrm{~mm}, 0,-50 \mathrm{~mm}$, weighted by fractional area collection rate). In the current simulation, an averaging procedure is needed to process particle properties from the discrete particle trajectories. The calculated values for the overall burnout are obtained by averaging all the particles passing a circular cross-section with a diameter of $120 \mathrm{~mm}$. The collection rate in this sampling area, with respect to the total flow rate through the entire cross section, varies at different axial locations (higher upstream than downstream). The relative collection rate is also dependent on the type of coal, typically about $62-65 \%$ at the probe port located at $925 \mathrm{~mm}$ from the lance tip, with a larger value corresponding to a lower burnout coal. Therefore a large proportion of particles have been counted to determine the overall burnout. A comparison of the overall burnouts calculated and measured for various cases is given in Table 5. The effect of several parameters on the coal burnout is discussed in more detail as below.

\subsubsection{Volatiles Content}

A comparison between the calculated and experimental burnouts is shown in Fig. 16 for coals (and coke) of varying proximate volatile matter contents $(0-35 \%)$. In Fig. 16(a), two coal flowrates are considered for each coal type, as listed in Table 5 for cases 1-7 corresponding to Coal A, $\mathrm{B}$ and $\mathrm{C}$. For the purpose of comparison, the case of $\mathrm{VM}=0$, i.e., the injection of coke powder is also considered. The calculation conditions assumed for this case are: (a) a composition of $10 \%$ ash and $90 \%$ carbon; (b) a particle flowrate of $35.8 \mathrm{~kg} / \mathrm{h}$, corresponding to an $\mathrm{O} / \mathrm{C}$ value (or atomic ratio of oxygen to carbon) of 1.9; and (c) coke pow- 


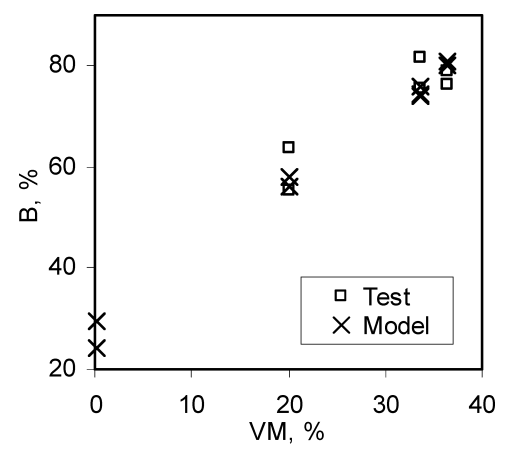

a)

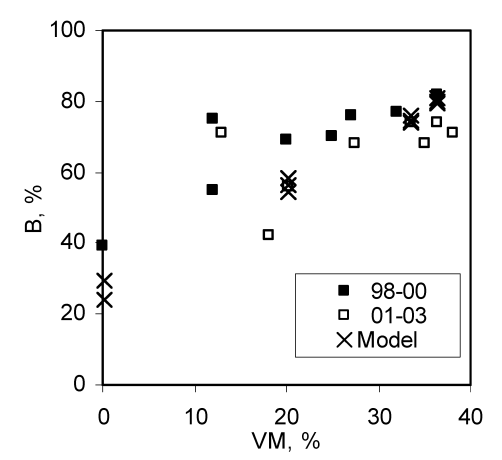

b)

Fig. 16. Effect of volatiles content on coal burnout and comparison with test data. (a) Case to case comparison; (b) overall comparison with test data including previous results after Mathieson et al. ${ }^{13)}$

der having the same size distribution as Coal A. As expected, both the calculated and experimental burnouts increase with the increase of volatile matter. There is also a satisfactory agreement between the experimental data and model calculations. It is worth noting that coke powder injection gives about $30 \%$ burnout. This appears to be reasonable according to the test data obtained previously, ${ }^{13)}$ although no test data are available for the current test setup. It can be seen from Fig. 16 that the discrepancy between data points is generally larger for low VM coals than for high VM coals, suggesting that the combustion efficiency of a low VM coal is more sensitive to the change of operating conditions.

The simulation results show that the emission and combustion of volatile matter takes place mainly near the tuyere. Therefore, experimental data generated specifically for this region will be critical to further validation of the model. Nevertheless, the two-competing devolatilisation model together with the chosen constants appears to describe the effect of volatile matter on the total burnout reasonably well. The simulated results indicate that a larger amount of VM is evolved per unit coal during the PCI process than the measured content from the proximate analysis. This is well accepted in the literature ${ }^{5)}$ and, in fact, a so-called Q-factor has been generated to describe this enhanced VM yield. The establishment of this factor needs to use a large scale experimental set-up to generate necessary data for correlation analysis, which is quite laborious. The numerical model proposed here can take account of the coal evolution behaviour quite readily without such a need.

\subsubsection{Particle Size}

It has already been noted that fine coal particles devolatilise and combust more rapidly than large particles.

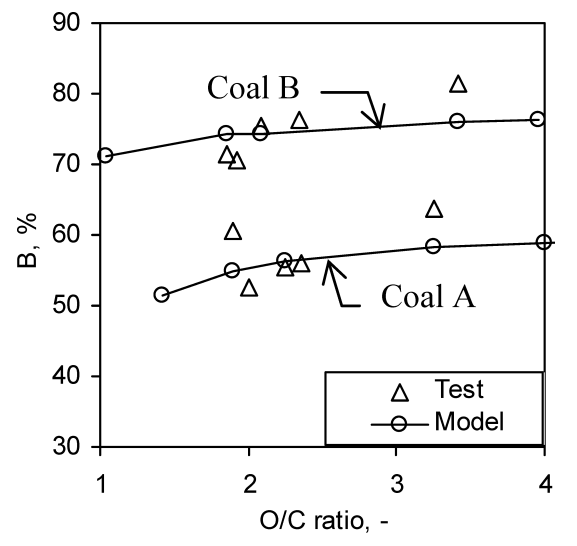

Fig. 17. Comparison between calculated and experimental results for three coals, showing the effect of coal injection rate on burnout.

Consequently, more rapid combustion of finer particles may actually affect the burnout of large particles, particularly as there is competition for oxygen during the latter char oxidation stage. In addition, a parametric study has shown that the mean particle size of the coal sample has an effect in the range of particle sizes considered here, i.e., when the other coal properties were kept fixed, a finer size distribution gave a higher burnout than a coarser one by $0.75-3.9$ percentage point (with a larger value corresponding to a lower volatile coal). For a low volatile coal, a lower mean size provides a higher specific particle surface area for the oxygen diffusion and char oxidation. Conversely, a high volatile coal is less sensitive to the mean particle size, because the final burnout relies mainly on the volatile yield, which is independent of particle size in the devolatilisation model.

\subsubsection{Coal Flowrate}

The coal injection mass flowrate was varied systematically while the other gaseous flowrates were maintained constant. Figure 17 shows the effect of coal flowrate (represented by the $\mathrm{O} / \mathrm{C}$ ratio, i.e., the total mole ratio of oxygen atoms to carbon atoms introduced in all the inflow streams) on the global burnout. From the experimental data, the burnout follows a general increasing trend with decreasing coal injection rate (increasing $\mathrm{O} / \mathrm{C}$ ), and this trend varies with coal type. The simulated trend shows that burnout does not increase linearly with the $\mathrm{O} / \mathrm{C}$ ratio, but a limiting value exists beyond $\mathrm{O} / \mathrm{C}=4$. On the other hand, over-supply of coal could lead to a quick drop in burnout.

The calculated burnout is consistent with experimental results, although the dependency on the coal flowrate appears to be slightly weaker, particularly for high VM coal. Decreasing burnout with increasing coal injection can be explained by the fact that the oxygen concentration within the plume is very low, and the char oxidation reaction rate will be limited by the oxygen supply from outside the plume. In the case of a high coal flowrate more oxygen is consumed and the diffusion of oxygen through the coal plume is low. For this reason, the burnout becomes less sensitive to the coal flowrate for increasing volatile matter content in the coal. Although the calculated burnout at $925 \mathrm{~mm}$ decreases with increasing coal flowrate, no such apparent trend is observed at an upstream location, e.g., near the tuyere outlet.

\subsubsection{Type of Cooling Gas}

A limited number of cases for methane cooling instead 
of air have been simulated. Figure 18 shows that methane is almost completely consumed mid-way along the tuyere. The distributions of gas temperature and composition are affected in the near field immediately after the lance tip. Preferential combustion of methane promotes the flame front (high temperature zone of the gas phase), which moves slightly outward in the radial direction to the interface between the methane flow and surrounding hot blast (Fig. 19). Coal burnout is slightly lower for methane cooling than for air cooling, since the introduction of the second fuel consumes extra oxygen, thus reducing the char oxidation rate. In the selected cases, since the mass flow rate of the methane is about $10 \%$ of the volatiles yield for high volatile coal above $32 \%$, the effect of this small amount on the coal burnout is not significant. However, for a low volatile coal, the char oxidation becomes more important, thus the effect of methane combustion becomes a little more pronounced. For example, in the case of the low volatile coal (Coal A), the model predicts that methane cooling reduces the burnout by 1.5 percentage points compared with air-cooling for the same coal flowrate of $36 \mathrm{~kg} / \mathrm{s}$. The burnout for Coal A decreases when cooling methane is used, while the dependency of the burnout for Coals B and $\mathrm{C}$ is hardly visible. These predictions are qualitatively consistent with the experimental observations, ${ }^{19)}$ but further work is required to assess systematically the effect of cooling gas for different coals.

\section{Conclusions}

A three-dimensional model of pulverised coal injection has been developed for simulating the flow and combustion in the tuyere and raceway of a blast furnace, without considering the coke reactions. This model is used to simulate the combustion in a test rig, with an inclined co-axial lance and a cooling gas. The predicted burnouts are comparable with those measured at $925 \mathrm{~mm}$ from the lance tip for three coals with volatile content ranging from $20.2-36.4 \%$ and particle sizes distribution ranging from $1-200 \mu \mathrm{m}$.

Many important phenomena in the test rig combustion chamber, such as flow asymmetry, recirculation flow and particle dispersion, have been predicted. Coal particles can be preheated and pyrolyse within the coal injection lance due to radiation from the downstream flame. The extent of radial dispersion of particles exiting from a simple straight lance is very limited in the tuyere, but more extensive in the combustion chamber. The entrainment of particles in the recirculating eddies results in chaotic particle trajectories in the test chamber.

The model indicates that volatile matter content of coal is largely responsible for its rapid combustion. Mean burnout increases with axial distance. Burnout increases rapidly at first (devolatilisation), but slows during char oxidation. Burnout is low at the centre of the plume, increasing radially. The present model can satisfactorily reproduce the experimental observations, such as the effects of coal flowrate and introduction of methane cooling on the coal burnout. These effects are stronger for a low volatile coal than for a high volatile coal.

Finally, as a model limitation, it is noted that the char oxidation model used produces higher burnout for fine particles at the near-wall region than the measurements. There has been evidence that the structural change of the char during char reaction reduces the char activity, ${ }^{28)}$ so that limiting burnout is expected. However, the char oxidation model does not take account of this reaction rate decrease or the petrographic constitution of the coal and the derived char morphotypes. Moreover, the numerical model has to some degree under-predicted the dependency of overall burnout on some variables such as the mean particle size, cooling gas and coal flowrate. This could also be related to the char oxidation model. Future work should focus on further validation of the char oxidation model and systematic parametric study.

\section{Acknowledgement}

The authors wish to acknowledge the financial support provided by BlueScope Steel and Australian Research Council. The assistance provided by Dr. Phil Stopford (ANSYS Europe Ltd.) and A/Prof. David Fletcher (University of Sydney) is gratefully acknowledged.

\section{REFERENCES}

1) K. Yamaguchi, S. Matsunaga, H. Ueno, K. Kakiuchi and S. Amano: CAMP-ISIJ, 7 (1994), 954.

2) R. Tao, J. Zhu and C. Cao: Proc. Int. Conf. Steel and Society, ISIJ, Tokyo, (2000), 93.

3) M. Sato, R. Murai, T. Ariyama, A. Maki, A. Shimomura and K. Mori: Tetsu-to-Hagané, 84 (1998), 37.

4) M. Sato, R. Murai and T. Ariyama: Tetsu-to-Hagané, 82 (1996), 731.

5) Advanced Pulverised Coal Injection Technology and Blast Furnace Operation, ed. by K. Ishii, Elsevier Science Ltd., Oxford, (2000), 83.

6) A. S. Jamaluddin, T. F. Wall and J. S. Truelove: Ironmaking Steelmaking, 13 (1986), 91.

7) T. Suzuki, L. D. Smoot, T. H. Fletcher and P. J. Smith: Combust. Sci. Tech., 45 (1986), 167.

8) J. C. He, M. Kuwabara and I. Muchi: Tetsu-to-Hagané, 72 (1986), 1847.

9) H. Nogami, T. Miura and T. Furukawa: Tetsu-to-Hagané, 78 (1992), 1222.

10) K. Takeda and F. C. Lockwood: ISIJ Int., 37 (1997), 432.

11) Z. Q. Li, F. Wei, Y. Jin: Chem. Eng. Sci., 58 (2003), 5161.

12) J. J. Nijdam, B. Guo, D. F. Fletcher and T. A. G. Langrish: Proc. 3rd Int. Conf. on CFD in Mineral and Process Industries, CSIRO, Melbourne, (2003), 377; submitted to Appl. Math. Model., (2005).

13) J. G. Mathieson, J. S. Truelove and H. Rogers: Int. Symp. on Utilisation of Coal and Biomass, ISUCB-03 Newcastle, Australia, (2003).

14) A. S. Jamaluddin: Ph.D. Thesis, University of Newcastle, Newcastle, (1985).

15) A. S. Jamaluddin, T. F. Wall and J. S. Truelove: 21 st Int. Symp. on Combustion, The Combustion Institute, Pittsburgh, (1986), 575.

16) R. J. Haywood, J. S. Truelove and M. J. McCarthy: Third Australian Flame Days, University of Newcastle, Newcastle, (1993), A4.3.1.

17) R. J. Haywood, M. J. McCarthy, J. S. Truelove, M. B. Mason and A. D. Thomson: 4th Australian Flame Days, University of Adelaide, Adelaide, (1995).

18) K. Goto, R. Murai, A. Murao, M. Sato, M. Asanuma and T. Ariyama: Int. BF Lower Zone Symp., AIMM (Illawarra Branch), Melbourne, (2005), 1-1.

19) H. Rogers: Private communications, (2004).

20) G. Clixby and R. R. Willmers: Proc. of 2nd European Ironmaking Cong., Institute of Metals, London, (1991), 434.

21) ANSYS CFX, CFX4.4 Online Document, (accessed 2004).

22) B. F. Magnussen: First Topic Oriented Technical Meeting-International Flame Research Foundation, Amsterdam, The Netherlands, (1989).

23) A. D. Gosman and E. Ioannides: J. Energy, 7 (1983), 482.

24) S. K. Ubhayakar, D. B. Stickler, C. W. von Rosenberg, Jr. and R. E. Gannon: Proc. of 16th Int. Symp. on Combustion, The Combustion Institute, Pittsburgh, (1976), 427.

25) H. Aoki, H. Nogami, H. Tsuge, T. Miura and T. Furukawa: ISIJ Int., 33 (1993), 646

26) J. Gibb: Lecture, Mechanical Engineering Dept., Imperial College, London, (1985).

27) B. D. Wright: Private communication, (2003).

28) L. M. Lu, V. Sahajwalla and D. Harris: Metall. Trans. B, 32B (2001), 811. 